\title{
MORPHOMETRIC STUDY OF THE SKULL OF THE WEST AFRICAN DWARF GOAT FROM SOUTH WEST NIGERIA
}

\author{
OLOPADE, J.O. AND ONWUKA, S.K. \\ Department of Veterinary Anatomy, Faculty of Veterinary Medicine \\ University of Ibadan, Ibadan, \\ Nigeria
}

\section{SUMMARY}

In this study, a total of thirty West African Dwarf (WAD) goats were used with fifteen parameters examined. The whole skull length and height were $16.99 \mathrm{~cm}$ and $9.15 \mathrm{~cm}$, respectively while the basal length was $14.88 \mathrm{~cm}$. The neurocranium length of $7.29 \mathrm{~cm}$ was higher than the $4.59 \mathrm{~cm}$ obtained for the neurocranium height while the skull height without the mandible was $7.51 \mathrm{~cm}$. The vertical diameter of the foramen magnum was greater than the transverse diameter thus giving a foramen magnum index of over 100. The intercondylar and interparacondylar widths were $4.09 \mathrm{~cm}$ and $4.20 \mathrm{~cm}$, respectively. The data in this study suggest that the WAD goat has shorter skull than the Anglo Nubian breed of goat.

The results are a valuable contribution to the pool being complied as part of an ongoing process of producing a data base information on the anatomy of small ruminants in Nigeria and will be important in the comparative anatomy of goats and clinical studies in the head region of the breed.

KEY WORDS: Morphometry, Skull, West African Dwarf Goat

\section{INTRODUCTION}

The West African Dwarf Goat (WAD) is an important breed of goats in Nigeria. They are indigenous to the coastal and rainforest regions of the country. The animal is of socio-economic importance to rural dwellers. It is very prolific, relatively resistant to diseases and thrives well in extensive system of animal management (Osuagwuh, 2002). There is an ongoing process of basic biomedical evaluation of goats in Nigeria (Olopade and Onwuka, 2002, 2003: Onwuka et al., 2003).

Skull typology and body dimensions are important criteria in the assessment of breeds of animals and their genetic profiles. These parameters can also be a basis for the study of interactions between heredity and environment (Dunlop, 1963, Onar 2001). Among domestic animals, skull typology has been more extensively studied in the dog (The and Trouth, 1976, Onar et al. 1997, Onar, 1999 and Onar et al. 2001) and then in the pig (Senba, 1964; Endo, 2002). There is however a dearth of information on the skull typology of goats and in particular the WAD.

The aim of this study therefore is to provide information on some aspects of the skull typology of WAD goats from South West Nigeria.

\section{MATERIALS AND METHODS}

A total of thirty WAD goats were used for the study with fifteen parameters measured. The animals were clinically examined for their state of health. Their heads, were after sacrifice, severed at the atlanto-occipital joint and the skulls were macerated according to the techniques of Onar (1999) and the University of Arizona 
extension paper (1999) on cleaning and skull preservation. The landmarks on the skull based on those described by Brehm et al. (1985), Evans and Christensen (1993) and Onar (1999) were measured using calibrated rules and vernier caliper. The results were evaluated and presented as means $\pm \mathrm{SD}$.

\section{Measurements in the skull}

The following measurements and appropriate indices were calculated.

- Whole skull length: From the cranial alveolar end of the mandible to the level of the nuchal crest.

- Whole skull height: From the highest level of the frontal bone to the lowest level of the mandible.

- Whole skull index: Max whole skull height $x$ 100/Whole skull length

- Skull height (without mandible): From the level of the highest point of the frontal bone to the base of the occipital condyle.

- Basal length: From the cranial alveolar end of the mandible to the occipital condyles at the level to the jugular process.

- Neurocranium height: From the deepest indentation of the sella turcica directly dorsal to the roof of the neurocranium.

- Neurocranium length: From the deepest indentation of the frontoethmoidal junction to the most distal surface of the cranium.

- Neurocranium index: Neurocranium height $x$ 100/Neurocranium length

- Foramen magnum height: Mid-vertical height of the foramen magnum

- Foramen magnum width: Largest width of the foramen magnum

- Foramen magnum index: Foramen magnum height $\times 100 /$ Foramen magnum width

- Occipital triangle height (without foramen magnum): from the nuchal crest to the upper brim of the foramen magnuim

- Length of corneal process: From the rostroventral line of the level of the horn corium to the tip of the bony horn.

- Intercondyular width: Width between the ends of the occipital condyles.

- Interparacondylar width: This is the greatest breadth of the ventromedial ends of the jugular processes.

\section{RESULTS}

TABLE 1: Data from-measurement of the skull of WAD (mean \pm sd

\begin{tabular}{ll}
\hline Item & Mean $\pm \mathrm{scl}$ \\
\hline Whole skull length $(\mathrm{cm})$ & $16.99 \pm 1.59$ \\
Whole skull height $(\mathrm{cm})$ & $9.15 \pm 1.27$ \\
Whole skull index & $55.11 \pm 5.6$ \\
Skull height (without mandible) & $7.51 \pm 0.58$ \\
(cm) & $14.88 \pm 1.61$ \\
Basal length $(\mathrm{cm})$ & $7.29 \pm 0.25$ \\
Neurocraniun length $(\mathrm{cm})$ & $4.59 \pm 0.73$ \\
Neurocranium height $(\mathrm{cm})$ & $165.77 \pm 9.24$ \\
Neurocranium index & $1.72 \pm 0.11$ \\
Foramen magnum height $(\mathrm{cm})$ & $1.67 \pm 0.16$ \\
Foramen magnum width $(\mathrm{cm})$ & $102.5 \pm 0.06$ \\
Foramen magnum index & $3.92 \pm 0.16$ \\
Occipital triangle height (without & \\
the foramen magnum) $(\mathrm{cm})$ & $3.17 \pm 1.03$ \\
Length of corneal process $(\mathrm{cm})$ & $4.09 \pm 0.27$ \\
Intercondylar width $(\mathrm{cm})$ & $4.20 \pm 0.15$ \\
Interparacondylar width $(\mathrm{cm})$ & \\
\hline
\end{tabular}

The whole skull length and height were $16.99 \pm 1.59 \mathrm{~cm}$ and $9.15 \pm 1.27 \mathrm{~cm}$, respectively. The whole skull index was therefore below 100. However, the foramen magnum height and width were $1.72 \pm 0.11 \mathrm{~cm}$ and $1.67 \pm 0.16 \mathrm{~cm}$ respectively, thus the foramen magnum index was slightly above 100 . The length of the corneal process was $3.17 \pm 1.03 \mathrm{~cm}$.

\section{DISCUSSION}

The whole skull length of the WAD goat was found to be $16.99 \pm 1.59 \mathrm{~cm}$. This result suggests that the WAD goat is 
shorter than the Anglo Nubian breed (Goat Skull, 2005) whose condylobasal length was reported in literature as $21.15 \mathrm{~cm}$. The condylobasal length is measured from the extreme end of the premaxilla bone to the caudal end of the skull and is slightly longer $(<1-2 \mathrm{~cm})$ than the whole skull length which rostral limit is from the alveolar extremity of the mandible. The condylobasal length of the WAD goat was not reported in this study due to damages that occurred to the premaxilla bone during processing. The basal length in this study was $14.88 \pm 1.62 \mathrm{~cm}$ and the skull height (excluding mandible) was $7.51 \pm$ $0.58 \mathrm{~cm}$. The interparacondylar width was $4.20 \pm 0.15 \mathrm{~cm}$; the equivalent in the Alsatian dog was $4.56 \pm 0.33$ (Onar et al., 1997). It was noted however that in the morphology of the WAD goat, the jugular processes were curved medially from their extended lateral wings towards the ventral portion and this was the part used as landmarks for morphology.

The width of the foramen magnum of the WAD goat was $1.67 \pm 0.16 \mathrm{~cm}$ while the height was $1.72 \pm 0.11 \mathrm{~cm}$; the equivalent values of these parameters in rabbit and Alsatian dogs were $1.15 \pm 0.04 \mathrm{~cm}, 0.86$ \pm 0.04 and $1.75 \pm 0.08 \mathrm{~cm}, 1.63 \pm 0.08 \mathrm{~cm}$ respectively (Kahcevioglu et al., 2000; Onar et al., 1997). This means that the foramen magnum is relatively higher in WAD goats but wider in Alsatian dogs and rabbits thus the foramen index of WAD goat was above $100(102.5 \pm 0.06)$ while those of rabbits and Alsatians were below 100 (74.78 \pm 4.05 , Kahvecioglu et al., 2000 and $92.67 \pm 6.75$, Onar et al., 1997 respectively). It has been reported (Sission, 1975) that although the transverse diameter was more often bigger than vertical diameter, the two sometimes had equal lengths. In some instances, the vertical diameter may be bigger. This was the situation in the WAD goat. This could provide a good reason for doing comparative morphometrical studies of the medulla oblongata and spinal cord areas of different species and breeds of animals (Dyce et al., 1996).

The foramen magnum in most of the goats examined showed the presence of a classical notch. This morphological observation seems to be normal and is consistent in the WAD goats examined in this study. Its occurrence has however been regarded as an occipital dysplasia and related to the clinical sign of congenital or acquired neurological diseases in small and middle sized brachycephalic breeds of dogs (De Lahunta, 1974; Simoens et al., 1994). No apparent neurological signs were however observed in these goats.

As earlier said, there is a dearth in literature on the skull typology of goats especially the WAD goat. We are at this point doing the skull typology of the Red Sokoto and Sahel goats, and also the WAD goat from the eastern part of Nigeria. These results will help to evaluate the differences between the WAD goat and other breeds of goats and also ascertain if geographical variation has an effect on skull typology of goats of the same breed (Endo, 2002). We thus conclude that the numerical information provided on some aspects of the anatomy of the head of WAD goat in this study will be useful in comparative anatomical studies between species of domestic animals and also between and within breeds of goats.

\section{ACKNOWLEDGEMENTS}

We thank Associate Professor Vedat Onar of Department of Veterinary Anatomy, University of Istanbu, Turkey for his reprints on the skull typology of dogs and Mr. Shina Ramoni of Department of 
Veterinary Anatomy, University of Ibadan, Nigeria for technical support.

\section{REFERENCES}

BREHMN, H., LOEFFLER, K. and KOMEYLI, H. (1985): Skull shape in the Dog. Anat, Histol, Embryol. 14: $324-331$.

De LAHUNTA, A. (1983); Veterinary Neuroanatomy and Clinical Neurology Second Ed. Saunders Co. Philadelphia London.

DUNLOP, A.A. (1963): Interaction between hereditary and environment in the Australian merino strain $\mathrm{X}$; Location interaction in body traits and reproduction performance. Aust. $J$. Agric. Res. 14: 690 - 703.

DYCE, K.M., SACK, W.O. and WENSING, C.J.G (1996): Textbook of Veterinary Anatomy. Second ed, Saunders co. Philadelphia..

EVANS, H.E and G.C. CHRISTENSEN (1993): Millers Anatomy of the Dog. Third Ed. Saunders Co. Philadelphia.

ENDO, H., HAYASHI, Y., YAMAZAKI, K., MOTOKAWA, M., PEI, J., LIN, L., CHOU, C. and OSHIDA, T. (2002): Geographical Variation of the Mandible Size and Shape in the Wile Pig (Susscrofa) from Taiwan and Japan. Zoological Studies 41:452-460.
GOAT SKULL. (2005):

www.wkull.co.uk.Goat.goat.htm.

KAHVECIOGLU, K.O., ONAR, V., ALPAK, $H$. and PAZVANT, G. (2000): The morphometry of the foramen magnum in rabbits and its correlation with craniometric measurements. Folia Veterinaria 44: 2: $62-69$.

ONAR, V., (1999): A morphometric study of the skull of the German shepherd dog (Alsatian). Anat. Histol. Embryol 28: 253 - 256.

ONAR, V., Mutus, R. and Kahvecioglu, K.O. (1987): Morphometric analysis of the foramen magnum in German Shepherd dogs (Alsatian). Ann. Anat. 179: 563 - 568.

ONAR, V., OZCAN, S. and PAZVANT, G. (2001): Skull Typology of the Adult male Kangal dog. Anat. Histol. Embryol. 30: 412 - 48.

OLOPADE, J.O. and ONWUKA, S.K. (2002): Preliminary morphometric investigation of the brain of Red Sokoto (Maradi) Goat. Trop. Vet., 21: $80-84$.

OLOPADE, J.O. and ONWUKA, S.K. (2003); A preliminary investigation to some aspects of the craniofacial indices of the Red Sokoto (Maradi) 